\title{
Optical and Physical Properties from Primary On-Road Vehicle Particle Emissions And Their Implications for Climate Change
}

\author{
AW. Strawa ${ }^{\mathrm{a} 1}$, TW. Kirchstetter ${ }^{\mathrm{b}}$, AG. Hallar ${ }^{\mathrm{a}, \mathrm{c}}$, GA. Ban-Weiss ${ }^{\mathrm{d}}$, JP. McLaughlin ${ }^{\mathrm{e}}$, RA. Harley ${ }^{\mathrm{e}}$, \\ MM. Lunden ${ }^{\mathrm{b}}$
}

aNASA-Ames Research Center, Moffett Field, CA 94035

${ }^{\mathrm{b}}$ Lawrence Berkeley National Laboratory, Atmospheric Science Dept., Berkeley, CA 94720

${ }^{\mathrm{c}}$ currently with Desert Research Institute, Storm Peak Laboratory, Steamboat Spring, CO 80488

${ }^{\mathrm{d}}$ University of California, Dept. of Mechanical Engineering, Berkeley, CA 94720

${ }^{\mathrm{e}}$ University of California, Dept. of Civil \& Environmental Engineering, Berkeley, CA 94720

\begin{abstract}
During the summers of 2004 and 2006, extinction and scattering coefficients of particle emissions inside a San Francisco Bay Area roadway tunnel were measured using a combined cavity ring-down and nephelometer instrument. Particle size distributions and humidification were also measured, as well as several gas phase species. Vehicles in the tunnel traveled up a $4 \%$ grade at a speed of approximately $60 \mathrm{~km} \mathrm{hr}^{-1}$. The traffic situation in the tunnel allows the apportionment of emission factors between light duty gasoline vehicles and diesel trucks. Cross-section emission factors for optical properties
\end{abstract}

\footnotetext{
${ }^{1}$ Corresponding author email: Anthony.W.Strawa@nasa.gov; phone: +1 650604 3437; fax: +1 650604 3625
} 
were determined for the apportioned vehicles to be consistent with gas phase and particulate matter emission factors. The absorption emission factor (the absorption crosssection per mass of fuel burned) for diesel trucks $\left(4.4 \pm 0.79 \mathrm{~m}^{2} \mathrm{~kg}^{-1}\right)$ was 22 times larger than for light-duty gasoline vehicles $\left(0.20 \pm 0.05 \mathrm{~m}^{2} \mathrm{~kg}^{-1}\right)$. The single scattering albedo of particles - which represents the fraction of incident light that is scattered as opposed to absorbed - was 0.2 for diesel trucks and 0.3 for light duty gasoline vehicles. These facts indicate that particulate matter from motor vehicles exerts a positive (i.e., warming) radiative climate forcing. Average particulate mass absorption efficiencies for diesel trucks and light duty gasoline vehicles were $3.14 \pm 0.88 \mathrm{~m}^{2} \mathrm{~g}_{\mathrm{PM}}{ }^{-1}$ and $2.9 \pm 1.07 \mathrm{~m}^{2} \mathrm{~g}_{\mathrm{PM}}{ }^{-1}$, respectively. Particle size distributions and optical properties were insensitive to increases in relative humidity to values in excess of $90 \%$, reinforcing previous findings that freshly emitted motor vehicle particulate matter is hydrophobic.

\section{Introduction}

Motor vehicle exhaust is a major contributor to climate change. In California, onroad motor vehicles account for $35 \%$ of the $\mathrm{CO}_{2}$ emissions $(C E C, 2006)$ and $9 \%$ of the $\mathrm{PM}_{2.5}$ emissions $(C A R B, 2006) . \mathrm{PM}_{2.5}$ is the mass of particulate matter with aerodynamic diameter less than $2.5 \mu \mathrm{m}$. Black carbon (BC) makes up $66 \%$ of fine particle emissions and, globally, transportation accounts for $20 \%$ of BC emissions by mass (Bond et al., 2004; Novakov et al., 2003). The amount of BC in the atmosphere is important to the balance of solar radiation because it absorbs solar radiation very effectively. This reduces the amount of energy reaching the surface, leading to a dimming at the surface, a redistribution of energy in the atmosphere, and impacting the hydrological cycle 
(Ramanathan and Carmichael, 2008). Estimates of the radiative forcing due to $\mathrm{BC}$ range from $+0.2 \pm 0.15 \mathrm{~W} \mathrm{~m}^{-2}$ (direct forcing only, (Forster et al., 2007) to between +0.5 to +1 $\mathrm{W} \mathrm{m}^{-2}$ (Hansen and Sato, 2001; Jacobson, 2001a; Menon, 2004; Ramanathan and Carmichael, 2008).

Many global climate models take particulate mass emissions from inventories, assume a size distribution, subject them to physical and chemical processes, and then obtain optical properties from look-up-tables calculated from standard or typical composition and size distributions (Menon, 2004). This methodology does not always yield satisfactory results. In one study the amount of BC in current aerosol inventories had to be increased by a factor of 2 to 4 for the global climate model to reach agreement with measurements (Sato et al., 2003). Model predictions of the effects that particles emissions, especially $\mathrm{BC}$, have on climate can be improved by more accurately measuring the optical properties at the emission source and relating them to fuel-based emission inventories.

Emission factors of $\mathrm{BC}$ and other carbonaceous material must be determined experimentally since these emissions are highly dependent on the fuel used, engine type and efficiency, fuel mixing rates, and vehicle load. Measurements of particulate matter emissions from vehicles are typically made in the laboratory using dynamometers, on road sides, and in traffic tunnels. Emission factors are generally reported for particulate matter, however, the operative parameters for purposes of visibility or climate effects extinction, scattering, or absorption coefficients - are typically not measured. The only studies that have reported measurements of optical properties of vehicle emission sources are Japar et al. (1981) and Szkarlat and Japar (1981), in which scattering and absorption 
from on-road vehicle exhaust in the Allegheny Tunnel were measured using a nephelometer and an integrating plate method. In this paper we report, for the first time, optical property emission factors in terms of optical cross sections per mass of fuel consumed in line with gas phase and other particulate mass (PM) emission factors. This makes it more convenient to assess the climatic effects of on-road vehicles based on fueluse inventories. Particle size distributions and the hydroscopicity of the emitted aerosol are presented.

\section{Methods}

\subsection{Field Site}

Vehicle gas phase and particulate emissions were measured at the Caldecott Tunnel in July of 2004 and July and August of 2006. The tunnel is located NE of San Francisco, CA. The tunnel is $1.0 \mathrm{~km}$ long, with a $4 \%$ grade uphill in the eastbound direction and has three separate two-lane traffic bores. This tunnel has been the site of periodic emissions monitoring since 1994 as part of an ongoing effort to study emission trends from the in-use vehicle fleet under natural driving conditions (Ban-Weiss et al., 2008b; Kirchstetter et al., 1999; Kirchstetter et al., 1996). Figure 1 shows the tunnel layout. The location of the optical measurements was on the east side of the traffic bore, as annotated on the figure. Instruments were set up on the exhaust duct floor and short sample lines of approximately $3 \mathrm{~m}$ were run through the vents in the ceiling of the tunnel to just below the ceiling. One of the advantages of measuring in the Caldecott tunnel is that heavy and medium duty diesel trucks are not allowed in the LDV bore, the center bore (referred to as the light duty vehicle (LDV) bore) whereas all vehicles were allowed 
in bore 1 (referred to as the mixed bore). Therefore, it is possible to use emission factors obtained for gasoline vehicles in the LDV bore to allocate emissions as being from $\mathrm{MD} / \mathrm{HD}$ diesel trucks or $\mathrm{LD}$ vehicles in the mixed bore using $\mathrm{CO}_{2}$ as a tracer (Ban-Weiss et al., 2008b). In the Caldecott tunnel, traffic counts indicate that $>99.4 \%$ of vehicles in the LDV bore were gasoline powered so it is reasonable to assume that the emissions apportioned to LD vehicles are due to the burning of gasoline fuel.

During the measurements vehicle speed was approximately $60 \mathrm{~km} \mathrm{~h}^{-1}$. Traffic in the mixed bore, bore 1, was always eastbound, or uphill, while the traffic pattern in the LDV bore, bore 2, varied throughout the day. The LDV bore was closed to traffic from midnight to approximately $4 \mathrm{am}$. Starting at about 4 am the LDV traffic was westbound, toward San Francisco, and emissions of vehicles just entering the tunnel were monitored. At about noon, the LDV bore was again closed to traffic for a short time and reopened to traffic eastbound, leaving the city, in the uphill direction. Optical properties were measured during the entire period, but filter measurements were made during intensive operating periods (IOPs) which occurred between $12 \mathrm{pm}$ and $2 \mathrm{pm}$ in the mixed bore and between $4 \mathrm{pm}$ and $6 \mathrm{pm}$ in the LDV bore to correspond to the rush hour periods when traffic was moving from west to east. Traffic counts were performed each day.

\subsection{Gas phase and Particle measurements}

Measurements made during the 2006 campaign included Nitrogen Oxides $\left(\mathrm{NO}_{\mathrm{X}}\right)$, Carbon Monoxide (CO), Carbon Dioxide $\left(\mathrm{CO}_{2}\right), \mathrm{PM}_{2.5}$, particle size distributions, $\mathrm{BC}$, organic carbon (OC), and the optical measurements that are the subject of this paper. Most measurements were made continuously throughout the measurement period. Filterbased measurements of $\mathrm{PM}_{2.5}$, total carbonaceous mass (TC), $\mathrm{BC}$ and $\mathrm{OC}$ were made 
only during the IOPs. Emission indices for $\mathrm{NO}_{\mathrm{X}}, \mathrm{PM}_{2.5}, \mathrm{OC}$, and $\mathrm{BC}$ were calculated using carbon balance methods described in section 2.4, and expressed per unit mass of fuel burned, separately for LD vehicles and medium/heavy duty (MD/HD) diesel trucks.

$\mathrm{PM}_{2.5}$ mass was collected on Teflon filters and measured gravimetrically. TC and $\mathrm{BC}$ were collected on quartz filters and determined using Thermo-Optical Analysis (TOA) (Kirchstetter et al., 2000). Estimated uncertainty for the gravimetric measurement and the TOA analysis is 5\% (Kirchstetter and Novakov, 2007; Watson et al., 2005). BC mass measurements were also made using an aethalometer. The aethalometer employs a filter-based optical transmission measurement commonly used to measure $\mathrm{BC}$ concentration by measuring aerosol optical absorption at $880 \mathrm{~nm}$. BC is the only commonly-found aerosol species that has a strong absorption in the infrared (Hansen, 2005a). The aethalometer measurement is essentially a measurement of absorption of aerosol that is deposited on a filter (Hansen, 2005a). The attenuation of a light beam shining through the filter is measured and converted to $\mathrm{BC}$ mass using a factor determined by the manufacturer; in this experiment a factor of $16.6 \mathrm{~m}^{2} \mathrm{~g}^{-1}$ was used and the measurements have been corrected for filter loading (Gundel et al., 1984; Hansen, 2005a). A standard unit provides a limit of detection (LOD, three times the mean noise level) of $\sim 300 \mathrm{ng} \mathrm{m}^{-3}$ for $1 \mathrm{~Hz}$ sampling at $6 \mathrm{~L} \mathrm{~min}^{-1}$ (personal communication w/ A. Hansen). It should be noted that the $\mathrm{BC}$ mass reported from the aethalometer was generally higher than the $\mathrm{BC}$ mass reported from the filter; averaged over the IOP measurements in each bore they were $10 \%$ higher in the mixed bore and $25 \%$ higher in the LDV bore. Given the reported uncertainties in these BC measurement methods (cf. 
Watson et al., 2005), we considered their agreement to be good. Organic mass (OM) was determined using the relationship $\mathrm{OM}=1.5 \times \mathrm{OC}$.

\subsection{Optical Properties}

During 2004 and 2006 measurements of aerosol optical properties were made with 1second temporal resolution using an instrument called Cadenza (Strawa et al., 2003; Strawa et al., 2006). Cadenza uses a cavity ring-down technique (O'Keefe and Deacon, 1988) to measure particulate extinction coefficient, $\sigma_{\mathrm{pe}}$, and simultaneously measures aerosol scattering coefficient, $\sigma_{\mathrm{ps}}$, using a reciprocal nephelometer technique (Mulholland and Bryner, 1994). Extinction and scattering coefficients were measured at $675 \mathrm{~nm}$ wavelength and extinction coefficients were measured at $1550 \mathrm{~nm}$ wavelength. Particle absorption coefficient, $\sigma_{\mathrm{pa}}$, and single scattering albedo, $\omega$, are determined at $675 \mathrm{~nm}$ from the difference and ratio of extinction and scattering, as shown below. The extinction Ångström exponent, å, is the negative of the slope of a log-log plot of $\sigma_{\text {pe }}$ vs wavelength (see Eq. (3)).

$$
\begin{aligned}
& \sigma_{p a}=\sigma_{p e}-\sigma_{p s} \\
& \varpi=\sigma_{p s} / \sigma_{p e}
\end{aligned}
$$

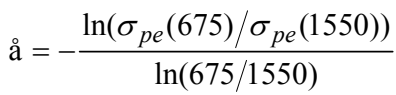

One advantage of the Cadenza over other techniques measuring optical properties is that the measurement of extinction and scattering are made in the same cell, at the same conditions, and with the same temporal resolution. Additionally, the measurements are not biased by changes in relative humidity and filter loading as are traditional instruments 
(such as the Particle Soot Absorption Photometer [PSAP]). Based on laboratory calibrations and experience with the instrument on aircraft we estimate that the uncertainty in the measurement of extinction and scattering coefficients is $2 \%$ and $7 \%$ at $675 \mathrm{~nm}$, respectively (Hallar et al., 2006; Schmid et al., 2006; Strawa et al., 2006), and $2 \%$ for the extinction coefficient at $1550 \mathrm{~nm}$. In a recent intercomparison measurements of extinction coefficient from Cadenza were compared to the sum of scattering measured with a nephelometer and absorption measured with a PSAP (Strawa et al., 2006). Agreement was within $2 \%$ for typical atmospheric values of up to several hundred $\mathrm{Mm}^{-1}$. Cadenza was also equipped with a humidification system (described below) to determine the hydroscopicity of vehicle emissions. The optical coefficients were measured at a relative humidity (RH) of less than $25 \%$ (dry) and greater than $90 \%$ (wet) during the IOPs. The measured optical properties and the effect of $\mathrm{RH}$, in addition to the particle size distribution (discussed below), represent the important parameters used to characterize the effects of particles on the radiation balance of the atmosphere.

\subsection{Emission Factors}

Emission factors were computed during IOP periods when vehicles traveled eastbound in the uphill direction using the carbon balance method shown in Equation 4 and described in Ban-Weiss et al. (2008). The emission factor, $\mathrm{E}_{\mathrm{p}}$, of a pollutant expressed as $\mathrm{g}$ of pollutant $\mathrm{kg}^{-1}$ fuel burned can be calculated as

$$
E_{P}=\left(\frac{\Delta[P]}{\Delta\left[\mathrm{CO}_{2}\right]+\Delta[\mathrm{CO}]}\right) w_{c},
$$

where $\Delta[P]$ is the background-subtracted (exit minus entrance) mass concentration of pollutant $P\left(\mu \mathrm{g} \mathrm{m}^{-3}\right)$, and $\Delta\left[\mathrm{CO}_{2}\right]$ and $\Delta[\mathrm{CO}]$ are the background subtracted 
concentrations in $\mathrm{mgC} \mathrm{m}{ }^{-3}$. It is assumed that most of the carbon is emitted as $\mathrm{CO}_{2}$ with smaller amounts emitted as CO (Kirchstetter et al., 1999). The fuel carbon mass fraction is $w_{c}=0.87$ for diesel and 0.85 for oxygenated gasoline (Kirchstetter et al., 1999). The optical property emission factor expressed as optical cross-section emitted per unit mass of fuel $\left(\mathrm{m}^{2} \mathrm{~kg}^{-1}\right)$ was calculated by replacing $\Delta[P]$ in Equation 4 with $\sigma\left(\mathrm{Mm}^{-1}\right)$. Since the optical properties were not measured at the tunnel entrance, the values of $\sigma_{p a}$ and $\sigma_{p s}$ at the entrance were estimated from the ratio of entrance to exit values of aethalometer and nephelometer measurements, respectively. For the LDV bore, that ratio for $\sigma_{p a}$ and $\sigma_{p s}$ was 0.19 and 0.32 , respectively. For the mixed bore, that ratio for $\sigma_{p a}$ and $\sigma_{p s}$ was 0.11 and 0.23 , respectively. Entrance values of $\sigma_{p e}$ were estimated by summing $\sigma_{p a}$ and $\sigma_{p s}$.

Emission factors for LD vehicles were calculated from the pollutant and optical property measurements made in the bore through which they exclusively traveled (LDV bore) and Equation (4). Emission factors for MD/HD trucks in the mixed bore could not be computed directly because LD vehicles contributed to the pollutant concentrations in that bore. First, the pollutants emitted in the mixed bore had to be apportioned to the two vehicle classes. The apportionment for each pollutant (or optical property) was done using estimates of $\mathrm{CO}_{2}$ emission from LDVs and pollutant to $\mathrm{CO}_{2}$ emission ratios measured in the mixed bore as

$$
\Delta[P]_{M, D}=\Delta[P]_{M}-\Delta\left[C O_{2}\right]_{M, G}\left(\frac{\Delta[P]_{L D}}{\Delta\left[C O_{2}\right]_{L D}}\right),
$$

where gasoline and diesel are denoted by the subscripts G and D, and the LD and mixed vehicle bores of the tunnel are denoted by LD and M subscripts, respectively. It was 
assumed that $53 \%$ of the medium-duty vehicles were diesel-powered (Ban-Weiss et al., 2008).

\subsection{Size Distributions}

Size distribution measurements were made using a TSI model 3081 Scanning Mobility Particle Sizer (SMPS). In 2004 the SMPS employed a TSI model 3025A Ultrafine Condensation Particle Counter CPC. In 2006 a TSI model 3786 Water-based Condensation Particle Counter (WCPC; on loan from TSI) was used. Scanning time in both cases was 2 minutes and distributions were averaged over the two-hour IOP. The system was set to obtain distributions from 20 to $820 \mathrm{~nm}$ in 2006. In 2004, the system was set to obtain distributions from 15.7 to $445 \mathrm{~nm}$ in the LDV bore and 15.7 to $638 \mathrm{~nm}$ in mixed bore. This size range was selected because previous studies demonstrated that the peak of the nucleation mode is typically near $15 \mathrm{~nm}$ (Geller et al., 2005; Kittelson, 1998). Distributions are corrected for efficiencies in the classifier and CPC but not for diffusional losses in either instrument or the sampling lines. Diffusional losses can be important for particles with diameters less than $100 \mathrm{~nm}$ and significant for particles with diameters less than $15 \mathrm{~nm}$. Kittelson et al., (2006a) estimate SMPS losses of 70\%, 35\%, and $12 \%$ at 10, 20 and $50 \mathrm{~nm}$, respectively, based on the calculations of Ayala et al. (Ayala et al., 2003). Measurement uncertainty for SMPS size distributions is limited by CPC counting accuracy and is considered to be about $\pm 12 \%(T S I, 2009)$.

\subsection{Hydroscopicity}

The humidification system consisted of Permapure PD 100P and FC 125 Nafion tubes. Sample air was pulled into the dry Nafion tube to reduce the RH to below $25 \%$. A valve directed the dry sample air either to the instruments for dry sampling or to the wet 
Nafion tube to be humidified to greater than $90 \%$ RH. After exiting the humidification system, size distributions and optical properties were obtained with the TSI SMPS and Cadenza, respectively. The humidity was measured within the Cadenza cell and at the exit of the SMPS. Typically the system took several minutes to transition from dry to wet RH and from wet to dry RH. Measurements with $\mathrm{RH}<25 \%$ and $\mathrm{RH}>90 \%$ are not included in the analysis. Humidification data was obtained for approximately an hour each day during the IOP periods in both bores, switching between dry and wet sampling every 10 minutes. The average volume mean diameter was calculated from the size distributions using the formula:

$$
V M D=\frac{1}{j} \sum_{j}\left(\sum_{i=D_{\min }}^{D_{\max }} 1.33 \frac{D_{i}^{3} d W_{i}}{D_{i}^{2} d W_{i}}\right)
$$

where $j$ refers to the number of size distribution with $\mathrm{RH}<25 \%$ for the dry case and $\mathrm{RH}>90 \%$ for the wet case; $D$ is the diameter and $d W$ is the concentration of the $i$ th size bin.

\section{Results}

\subsection{Optical properties and diurnal trends}

Table 1 lists measurements of particulate properties averaged over the 2 hour IOPs for 13 days in 2006 . The absorption coefficients $\left(\sigma_{\mathrm{pa}}\right)$ were derived from the difference of extinction $\left(\sigma_{\mathrm{pe}}\right)$ and scattering $\left(\sigma_{\mathrm{ps}}\right)$ coefficients measured by Cadenza at $675 \mathrm{~nm}$, and the single scattering albedo $(\omega)$ was derived from the ratio of scattering over extinction. Averaged over all IOPs, the values of $\sigma_{\mathrm{pe}}, \sigma_{\mathrm{ps}}, \sigma_{\mathrm{pa}}$, and $\omega$ in the LDV bore were $155 \pm 3.1$ $\mathrm{Mm}^{-1}\left(1.55 \times 10^{-4} \mathrm{~m}^{-1}\right), 52 \pm 3.7 \mathrm{Mm}^{-1}, 103 \pm 7.2 \mathrm{Mm}^{-1}$, and $0.34 \pm 0.02$ respectively. These 
amounted to $50 \%, 69 \%, 43 \%$, and $71 \%$ of the values in the mixed vehicle bore. The IOPaverage values of $\sigma_{\mathrm{pe}}, \sigma_{\mathrm{ps}}, \sigma_{\mathrm{pa}}$, and $\omega$ in the mixed bore were $310 \pm 6.2 \mathrm{Mm}^{-1}, 75.5 \pm 35.3$ $\mathrm{Mm}^{-1}, 241.6 \pm 16.9 \mathrm{Mm}^{-1}$, and $0.24 \pm 0.02$ respectively.

Five minute averages of $\sigma_{p e}, \sigma_{p s}, \sigma_{p a}$, and $\omega$ were binned to examine the average diurnal cycle in the two bores. A comparison of LDV and mixed bores for the 2006 campaign is shown in Figure 2. Values of the extinction and absorption coefficient are very low in the morning and increase dramatically during the day. In contrast, scattering coefficients increase only slightly during the day. Scattering coefficients were much lower than absorption coefficients during the day when vehicle activity was significant. $\omega$ decreased in the daytime because absorption increased more than scattering. Predawn $\omega$ was relatively high, about 0.55 in the mixed bore and about 0.7 with jumps to almost 1.0 in the LDV bore. Referring to Figure 2 d, it is a bit surprising that the values of $\omega$ did not recover to values more typical of the open atmosphere (i.e., $>0.9$ ) during the night, especially in the LDV bore when it was closed to traffic. These measurements suggest that emissions from traffic leaving the mixed bore (east end) are entrained into the LDV bore. This is corroborated by the gas phase measurements (Ban-Weiss et al, 2008b). Since our instruments were at the east end, they would measure these entrained emissions.

Figure 3 compares measurements for the mixed bore from the 2006 and 2004 campaigns. Measurements of aerosol optical properties were not obtained in the LDV bore during 2004. Agreement between the two years is good, although $\sigma_{p s}$ values are larger in 2004 than 2006, resulting is slightly higher values of $\omega$. These differences are 
probably within the normal variations experienced in the tunnel and are not considered significant.

\subsection{Optical properties and emission factors for $L D$ and $M D / H D$ vehicles}

Traffic counting data indicated that traffic in the mixed bore was composed of $93 \%$ LD vehicles and 7\% diesel trucks. While comprising a minority of the vehicle population in the mixed vehicle bore, the pollutant apportionment (described in section 2.4) indicated that diesel trucks produced most of the emissions (see Table 2).

Mass extinction efficiency (MEE), mass scattering efficiency (MSE), and mass absorption efficiency (MAE $\mathrm{PM}_{\mathrm{PM}}$, are a measure of how efficiently a mass of particulate matter scatters and/or absorbs light at the measurement wavelength. These are calculated separately for LD vehicles and diesel trucks using Equation 4, and are tabulated in Table 2. For LD vehicles, MEE, MSE, and $\mathrm{MAE}_{\mathrm{PM}}$ were $4.17 \pm 1.38,1.29 \pm 0.39$, and $2.9 \pm 1.07$ $\mathrm{m}^{2} \mathrm{~g}_{\mathrm{PM}}$, respectively. Diesel truck efficiencies were $3.99 \pm 1.12,0.78 \pm 0.24$, and $3.14 \pm 0.88$ $\mathrm{m}^{2} \mathrm{~g}_{\mathrm{PM}}$ for MEE, MSE, and MAE $\mathrm{PM}$, respectively.

Average extinction $\left(\mathrm{EF}_{\mathrm{e}}\right)$, scattering $\left(\mathrm{EF}_{\mathrm{s}}\right)$, and absorption $\left(\mathrm{EF}_{\mathrm{a}}\right)$ cross section emission factors indicate the optical proerty cross-section per unit mass of fuel consumed and is important in determining the radiative effects of vehicles from an emission inventory. For $\mathrm{LD}$ vehicles, $\mathrm{EF}_{\mathrm{e}}, \mathrm{EF}_{\mathrm{s}}$, and $\mathrm{EF}_{\mathrm{a}}$ were $0.29 \pm 0.05,0.09 \pm 0.009$, and

$0.20 \pm 0.05 \mathrm{~m}^{2} \mathrm{~kg}_{-}$fuel $^{-1}$, respectively. Average $\mathrm{EF}_{\mathrm{e}}, \mathrm{EF}_{\mathrm{s}}$, and $\mathrm{EF}_{\mathrm{a}}$ for diesel trucks were $5.6 \pm 1.02,1.1 \pm 0.23$, and $4.4 \pm 0.79 \mathrm{~m}^{2} \mathrm{~kg}_{-}$fuel ${ }^{-1}$, respectively.

\subsection{Particle size distribution and hydroscopicity}


Average number size distributions of particles measured in each tunnel bore during the 2004 and 2006 IOPs are shown in Figure 4. Size distributions were averaged over each two-hour IOP and then the 4 days (Mon. thru Thurs.) of measurement to obtain a single average distribution for each vehicle bore. The average distribution is more meaningful than any single distribution because each distribution was measured (i.e, scanned) over a two minute period, during which time individual vehicle emissions would influence the size distribution.

Two distinct modes can be seen in the 2006 size distributions: a nucleation mode ( $<$ $40 \mathrm{~nm}$ diameter) and an accumulation mode (between 40 and $400 \mathrm{~nm}$ diameter). In 2004, the accumulation mode was not as pronounced in the size distribution and there appears to be a third mode for particles with diameters greater than $400 \mathrm{~nm}$. The distribution measured in the mixed-vehicle tunnel bore in 2004 is fuller in the optically active sizes greater than $200 \mathrm{~nm}$. Measurements of $\sigma_{\mathrm{pe}}$ made in 2004 were generally slightly higher than in 2006. In both years, the mixed bore distributions had higher concentrations than the LDV bore which is to be expected. The difference between the LDV and mixed bores in 2004 was greater than in 2006. All distributions, but especially those taken in the mixed bore, show a distinct mode at about 100 to $150 \mathrm{~nm}$ that is very likely due to the emission of fresh BC (Kittelson et al., 2000). The total concentration for the mixed bore is about twice that of the LDV bore.

An example of particle extinction coefficient and volume mean diameter obtained during humidification experiments (where $\mathrm{RH}$ was switched from low and high every 10 minutes) in the MD/HDV bore is shown in Figure 5. The volume mean diameter is calculated directly from the number size distribution using Equation 6 every 5 minutes. 
As noted above and apparent in Figure 5, particle concentrations in the tunnel were variable on time scales shorter than the scanning time of the SMPS (2 min) and the switching interval from high to low RH. To minimize the effect of this variability, 5 days worth of IOP data were averaged to obtain single values of extinction and volume mean diameter. These values are shown in Table 3. (Insufficient data were collected to obtain volume mean diameter during humidification experiments in the LD vehicle bore.) In the $\mathrm{MD} / \mathrm{HD}$ vehicle tunnel bore, the average dry and wet $\mathrm{RH}$ were $23 \pm 2 \%$ and $92 \pm 2 \%$. The average dry and wet extinction were $103.4 \pm 3.0 \mathrm{Mm}^{-1}$ and $103.6 \pm 3.0 \mathrm{Mm}^{-1}$ and the average dry and wet volume mean diameter were 204.2 and $202.1 \mathrm{~nm}$. Uncertainty in the volume mean diameter is approximately $17 \%$, based on the uncertainty in the size distribution measurement. In the LD vehicle bore, the average dry and wet RH were $24 \pm 2 \%$ and $91 \pm 2 \%$, while the average dry and wet extinction coefficient was $290 \pm 6.2$ $\mathrm{Mm}^{-1}$ and $262 \pm 6.2 \mathrm{Mm}^{-1}$. Thus, changing the relative humidity of the sample in the 20$90 \%$ range had no significant effect on the particle size or the extinction coefficient in either tunnel bore. These results indicate that fresh exhaust emissions from LD vehicles and diesel trucks are hydrophobic.

\section{Discussion}

\subsection{Optical Properties}

The single scattering albedo $(\omega)$ in the mixed fleet tunnel bore during daytime periods, when diesel trucks dominated the particle emissions was largest, was approximately 0.2 , as shown in Figures 2 and 3. This value is much lower than values reported for ambient aerosols, and is similar to the $\omega$ of fresh, uncoated $\mathrm{BC}$ particles 
generated with an inverted diffusion flame (Kirchstetter and Novakov, 2007) and fresh particulate emissions from cookstove fires (Roden et al., 2006). The value measured in this study is consistent with Bond and Bergstron (2006), who recommended the use of 0.2 to 0.3 for the range in $\omega$ for fresh light absorbing carbonaceous aerosol.

Mass-averaged optical property efficiencies for the individual bores can be obtained by dividing the optical coefficients listed in Table 1 by $\mathrm{PM}_{2.5}$. Average MEE are $3.0 \mathrm{~m}^{2} \mathrm{~g}$ ${ }^{1}$ in the mixed bore and $2.6 \mathrm{~m}^{2} \mathrm{~g}^{-1}$ in the LDV bore. Average values of MSE were $0.65 \mathrm{~m}^{2}$ $\mathrm{g}^{-1}$ in the mixed bore and $0.8 \mathrm{~m}^{2} \mathrm{~g}^{-1}$ in the LDV bore, much lower than the value obtained for typical MSE for submicron particles in ambient air that are reported as $3 \mathrm{~m}^{2} \mathrm{~g}^{-1}$ (Malm et al., 1994) and $5 \mathrm{~m}^{2} \mathrm{~g}^{-1} \mathrm{Japar}$, et al. (1981) presumably because various organic and inorganic volatile species have not had time to condense and grow to optically active sizes, greater than about $200 \mathrm{~nm}$. Average MAE was $2.3 \mathrm{~m}^{2} \mathrm{~g}^{-1}$ in the mixed bore and 1.8 $\mathrm{m}^{2} \mathrm{~g}^{-1}$ in the LDV bore. Japar, et al. (1981) report an MAE value of $1 \mathrm{~m}^{2} \mathrm{~g}^{-1}$ for ambient aerosol.

Figure 6 shows the correlation between optical properties and more commonly measured parameters: a) $\sigma_{p e}$ and $\mathrm{PM}_{2.5}$, b) $\mathrm{BC} / \mathrm{TC}$ ratio and $\omega$, and c) $\mathrm{PM}_{2.5}$ and $\mathrm{BC}$ mass. The linear regression between extinction coefficient and $\mathrm{PM}_{2.5}$ has a slope of 3.47 and an $\mathrm{R}^{2}=0.84$. Single scattering albedo has an inverse relation with the $\mathrm{BC} / \mathrm{TC}$ ratio as expected since $\mathrm{BC}$ is more absorbing than other carbonaceous material. The regression slope is -0.44 with an $\mathrm{R}^{2}=0.77$. The points cluster in two groups, with higher $\omega$ associated with the LDV bore and lower $\omega$ associated with the mixed bore. These relations can be used to infer the optical properties of particulate matter in a previous study in the same roadway tunnel (Kirchstetter et al., 1999). In 1997 average $\mathrm{PM}_{2.5}$ 
concentrations were 132 and $55 \mu \mathrm{g}-\mathrm{m}^{-3}$ for the mixed and LDV bores, respectively, while in 2006 they were 88 and $46 \mu \mathrm{g}-\mathrm{m}^{-3}$ for the mixed and LDV bores, respectively. Using the 1997 values for $\mathrm{PM}_{2.5}$ and applying a linear least squares fit to the data in Figure 6a gives average extinction coefficients of $473 \mathrm{Mm}^{-1}$ and $195.4 \mathrm{Mm}^{-1}$ in 1997 for the mixed and LDV bores, respectively. These can be compared with $266.21 \mathrm{Mm}^{-1}$ and $120.03 \mathrm{Mm}^{-}$ ${ }^{1}$ for the mixed and LDV bores in 2006. The BC/TC ratios in 1997 were 0.59 and 0.36 for the mixed and LDV bores. These values compared favorably with ratios of 0.69 and 0.49 in 2006. Using the 1997 values for the BC/TC ratio and assuming a linear lest-squared fit to the data in Figure $6 \mathrm{~b}$ yields values for $\omega$ of 0.22 and 0.34 for the mixed and LDV bores in 1997 , respectively, compared with 0.24 and 0.34 in 2006 . Thus, although there was a lower concentration of particulate in 2006 than in 1997, the proportion of absorbing particulate was approximately the same. Figure 6c shows that $\mathrm{PM}_{2.5}$ correlates well with BC. The slope is 1.45 and the $\mathrm{R}^{2}$ is 0.85 .

Figure 7 shows probability density functions (PDF) of $\omega$ and å for both bores. The å is a measure of the effective radius of the particle size distribution, and $\omega$ is a measure of the absorbing properties of the particles. The most probable å is about 1.0 which we have found in the laboratory to be typical of accumulation mode particle sizes when $\AA$ is derived from extinction measurements made at wavelengths of $675 \mathrm{~nm}$ and $1550 \mathrm{~nm}$. There is a significant difference in the distributions of single-scattering albedo for the bores. The PDF for the LDV bore is broad and the most probable $\omega$ is 0.4 , while the mixed bore PDF is concentrated at lower $\omega$. The most probable $\omega$ for the mixed bore is 0.2 . The value of $\omega$ for both bores is very low indicating a strongly absorbing aerosol. 


\subsection{Optical properties and emission factors for $L D$ vehicles and $M D / H D$ diesel trucks}

The $\mathrm{PM}_{2.5}$ mass normalized absorption efficiencies (MAE $\mathrm{MM}_{\mathrm{PM}}$ ) of diesel trucks and $\mathrm{LD}$ vehicles were comparable $\left(3.14 \mathrm{~m}^{2} \mathrm{~g}_{\mathrm{PM}}{ }^{-1}\right.$ for diesel and 2.90 for $\left.\mathrm{LD}\right)$ and significantly below the mass absorption efficiency of $7 \mathrm{~m}^{2} \mathrm{~g}_{\mathrm{PM}}{ }^{-1}$ used in some climate models (Pozzoli et al., 2008; Verma et al., 2008). However, several modeling studies predict that the mixing state of $\mathrm{BC}$, whether externally or internally mixed with other constituents, has a considerable effect on the amount of solar energy the particles absorb and can enhance the direct radiative forcing of this type of aerosol (Chung and Seinfeld, 2002; Haywood et al., 1979; Jacobson, 2001b; Myhre et al., 1998). Calculations by Bond and Bergstrom (2006) using a core/shell model suggest absorption of aged BC is enhanced 1.5 times greater than that of fresh BC. Schnaiter et al. (2005) measured absorption enhancements of 1.8 to 2.1 for $\mathrm{BC}$ coated with organic matter relative to externally mixed, $\mathrm{BC}$ in agreement with their core-shell Mie calculations. The MAE per mass of BC calculated in the present study (see Table 2) for diesel trucks this is $5.1 \mathrm{~m}^{2} \mathrm{~g}_{\mathrm{BC}}{ }^{-1}$ and for $\mathrm{LD}$ vehicles is $9.2 \mathrm{~m}^{2} \mathrm{~g}_{\mathrm{BC}}{ }^{-1}$. This result may seem surprising because $\mathrm{BC}$ comprises a greater portion of the particles emitted from diesel trucks (e.g., the $\mathrm{BC} / \mathrm{PM}_{2.5}$ ratio for diesel and gasolinepowered vehicles was 0.61 and 0.31 , respectively), however the larger MAE per mass of $\mathrm{BC}$ for $\mathrm{LD}$ vehicles may be due the fact that the $\mathrm{BC}$ emitted by $\mathrm{LD}$ vehicles is internally mixed with more $\mathrm{OC}$ than the $\mathrm{BC}$ from diesel trucks.

Our past measurement of fresh $\mathrm{BC}$ in an inverted diffusion flame at the Lawrence Berkeley National Laboratory and in the Caldecott tunnel produced MAE values of about $5.5 \mathrm{~m}^{2} \mathrm{~g}_{\mathrm{BC}}{ }^{-1}$ (at $675 \mathrm{~nm}$ wavelength), slightly higher than the tunnel value of $5.1 \pm 0.93$ $\mathrm{m}^{2} \mathrm{~g}_{\mathrm{BC}}{ }^{-1}$ for diesel trucks suggesting that the $\mathrm{BC}$ sampled from the diesel trucks (MAE $=$ 
$4.78 \mathrm{~m}^{2} \mathrm{~g}_{\mathrm{BC}}{ }^{-1}$ ) were nearly pure $\mathrm{BC}$. Assuming that the MAE has a spectral dependence inversely proportional to the wavelength of light (i.e., $\sigma_{\mathrm{pa}} \sim \lambda^{-1}$ ), which is the theoretical value for small absorbing particles, (Bergstrom et al., 2002; Bruce et al., 1991; van de Hulst, 1957), the MAE for diesel emissions in this study can be extrapolated to 6.3 $\mathrm{m}^{2} \mathrm{~g}_{\mathrm{BC}}{ }^{-1}$ at $550 \mathrm{~nm}$, close to the value of $7.5 \pm 1.2 \mathrm{~m}^{2} \mathrm{~g}^{-1}$ for fresh light absorbing aerosol suggested by Bond and Bergstrom (2006).

In 1979 Japar et al. (1981) measured MAE from on-road vehicle exhaust in the Allegheny Tunnel using an integrating plate method for absorption at a wavelength of $550 \mathrm{~nm}$. They report a MAE normalized by the particulate mass for gasoline vehicles of 8 and for diesel trucks of 5.13. Using a laser spectrophone, Szkarlat and Japar (1981) measured an MAE of 8.9 at $514.5 \mathrm{~nm}$ wavelength. While these efficiencies are cited as being referenced to $\mathrm{PM}$, they compare better with the efficiencies referenced to $\mathrm{BC}$ mass in the present study.

MSE, reported in Table 2, are lower for diesel trucks (an average value of $0.78 \pm 0.24$ ) than for LD vehicles (an average value of $1.29 \pm 0.39$ ), at a wavelength of $675 \mathrm{~nm}$. The wavelength dependence of scattering is a strong, non-linear, function, dependent on the composition and size of the aerosol, therefore it is inappropriate to convert our measurements at $675 \mathrm{~nm}$ to other wavelengths without an indication of the wavelength dependence of scattering. Japar et al. (1981) measured MSE of 1.99 for diesel trucks and 6 for LD vehicles using an integrating nephelometer both at $500 \mathrm{~nm}$, substantially higher than the present study.

From Table 2 it is seen that MD/HD diesel trucks emit 20 times more $\mathrm{PM}_{2.5}$ than gasoline LDV, $1.4 \mathrm{~g} \mathrm{~kg}$ _fuel $^{-1}$ vs $0.07 \mathrm{~g} \mathrm{~kg} \_$fuel $^{-1} ; 13$ times more organic matter, $0.41 \mathrm{~g}$ 


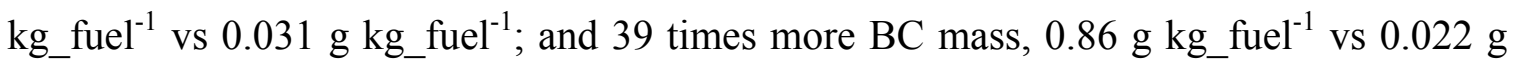
$\mathrm{kg}_{-}$fuel ${ }^{-1}$. This later value agrees with Rose et al., (2006), who found that trucks emitted more than 40 times higher soot concentrations than cars.

$\mathrm{PM}_{2.5}$ emission factors (PMEF) are also reported in Table 2 in units of $\mathrm{g} \mathrm{km}^{-1}$ using values of fuel economy (13.1 km kg${ }^{-1}$ for gasoline and $3.4 \mathrm{~km} \mathrm{~kg}^{-1}$ for diesel, (Ban-Weiss et al., 2008a)). The values for PMEF in this study become $0.005 \mathrm{~g} \mathrm{~km}^{-1}$ for LD vehicles and $0.412 \mathrm{~g} \mathrm{~km}^{-1}$ for diesel trucks. Jones and Harrison (2006) obtained values of PMEF =

$0.01 \mathrm{~g} \mathrm{~km}^{-1}$ for LDV and $0.179 \mathrm{~g} \mathrm{~km}^{-1}$ for HDV in a heavily trafficked street canyon in London. Differences in these measurements may be attributed to the presence of diesel passenger vehicles in the LDV pool, and the fact that the tunnel measurements were made for a $4 \%$ uphill incline.

\subsection{Particle size distribution and hydroscopicity}

One feature in the mixed bore size distributions shown in Figure 4 is that the concentrations for the larger sizes $(\mathrm{D}>200 \mathrm{~nm})$ are lower in 2006 than in 2004. As mentioned, the $3025 \mathrm{CPC}$ was used in 2004 and the 3786 WCPC was used in 2006. In past comparisons, good agreement has been found between the TSI model 3786 WCPC and the TSI model 3025 CPC (Biwas et al., 2005; Hering and Stolzenburg, 2005; Liu et al., 2008; Petäjä et al., 2007). Petäjä et al. (2007) found that the solubility of the particles to water did play a role in the detection efficiency of small particles $\left(D_{\mathrm{p}}<20 \mathrm{~nm}\right)$. It is unlikely that the engine performance changed in the intervening 2 years. The average model year for LD, MD, and HD vehicles was 2000.3, 2000, and 1997, respectively (Ban-Weiss et al., 2008). At present, the cause of the discrepancy in the two mixed-bore size distributions is unknown. 
There are many published measurements of vehicle size distributions made under various conditions. For example, Ban-Weiss et al. (this issue), Geller et al. (2006), measured in traffic tunnel ventilations ducts; Kittelson et al. (2006a; Kittelson et al., 2006b) measured in a laboratory and with a chase vehicle; Weingartner et al. (1997) measured at a traffic tunnel exit, Ketzel et al. (2003) and others measured in a street canyon, and Wehner et al. (2009) measured in traffic at the vehicle tailpipe. It is difficult to compare these published size distributions because different venues will result in vary different aging and dilution scenarios and road conditions, speed, grade, etc. cause vehicles to emit at different rates. Additionally, the composition of the fleet varies by venue. For example, size distributions for gasoline- and diesel-powered passenger cars under real traffic conditions were obtained using a new technique that positions sampling probes with $0.5 \mathrm{~m}$ of the tailpipe (Wehner et al., 2009). The size distributions obtained for the gasoline-powered car is similar to the LDV-only size distribution in this study, although of lower magnitude. The magnitude of the size distribution obtained for the diesel-powered car is much lager than that obtained in either bore in this study but the biggest difference is that the peak of the diesel-powered car distribution is about $60 \mathrm{~nm}$ whereas the peak of the distributions in the present study is below $20 \mathrm{~nm}$. The difference size distribution shapes means that comparisons between size distribution and number density emission factors of LDV in the US (predominantly gasoline-powered) are not comparable with size distributions and number density emission factors of LDV in Europe or other locations where the fraction of diesel-powered LDV is higher. The most direct comparison to the size distributions measured in this study are Ban-Weiss et al., 
(this issue) and Geller et al.(2005). The size distributions agree well in the regions where they overlap.

A closure calculation can be performed between the measured size distributions of Figure 4 and the measured particulate mass listed in Table 1 if certain assumptions are made. Integrating the size distributions of Figure 4, we obtain total particle number densities of $1.80 \times 10^{5} \# \mathrm{cc}^{-1}$ for the LDV-only bore and $2.67 \times 10^{5} \# \mathrm{cc}^{-1}$ for the mixed bore in 2006. The values for 2004 are $6.76 \times 10^{4} \mathrm{Acc}^{-1}$ in the LDV-only bore and $2.41 \mathrm{x}$ $10^{5} \# \mathrm{cc}^{-1}$ for the mixed bore. Assuming spherical particles, volume distributions of 44.2 $\mu \mathrm{m}^{3} \mathrm{cc}^{-1}$ for the LDV-only bore and $78.2 \mu \mathrm{m}^{3} \mathrm{cc}^{-1}$ for the mixed bore in 2006 are obtained. The values for 2004 are $55.8 \mu \mathrm{m}^{3} \mathrm{cc}^{-1}$ for the LDV-only bore and $198.0 \mu \mathrm{m}^{3} \mathrm{cc}^{-}$ ${ }^{1}$ for the mixed bore. The large decrease in volume distribution for the mixed bore between 2004 and 2006 is due to the reduction in size distribution in the larger sizes for the 2006 size distribution. The effective density for vehicle exhaust particles measured by mobility techniques varies from $0.3 \mathrm{~g} \mathrm{cc}^{-1}$ to $1.2 \mathrm{~g} \mathrm{cc}^{-1}$, depending on particle size (Maricq and Xu, 2004; Park et al., 2003). Using the median effective density of $0.75 \mathrm{~g}$ $\mathrm{cc}^{-1}$ we obtain particulate mass, $\mathrm{PM}_{0.8}$ equal to $33.2 \mu \mathrm{g} \mathrm{m}^{-3}$ and $58.6 \mu \mathrm{g} \mathrm{m}^{-3}$ for LDV-only and mixed bores, respectively in 2006 . These values are slightly below the bore-average $\mathrm{PM}_{2.5}$ values of $46.2 \mu \mathrm{g} \mathrm{m}^{-3}$ and $88.0 \mu \mathrm{g} \mathrm{m}^{-3}$ for LDV-only and mixed bores, respectively, that were measured in this study. This difference is the result of the contribution of vehicle exhaust, crankcase emission, and roadway dust to the larger sizes of the fine particulate mass.

Our results reinforce earlier suggestions that hydroscopic growth by freshly emitted traffic-generated aerosols is minimal at relative humidities below saturation, agreeing 
with the laboratory studies of Weingartner et al., (1997) that freshly emitted combustion particles are unlikely to act as cloud condensation nuclei. Using particles directly created by a diesel engine (load $1 \mathrm{~kW}$, no fuel additives and no pre-treatment), Weingartner et al. (1997) only saw a significant growth factor at a higher relative humidity than reached in our experiment $(95 \%)$.

\subsection{Implications for Climate Change}

It is important for regulators and policy makers to have estimates of the relative effects of LD vehicle and diesel truck emissions on climate change. Table 2 compares the emission factors and optical properties of particles emitted from LD vehicles and MD/HV diesel trucks. On the basis of fuel consumed and miles driven, respectively, MD/HD diesel trucks emit 39 and 150 times the mass of BC of gasoline vehicles. From a climate perspective, it is appropriate to compare absorption emission factors since the amount of light absorbed rather than the mass of particles emitted warms the atmosphere. The particles emitted when $\mathrm{MD} / \mathrm{HD}$ trucks consume a $\mathrm{kg}$ of diesel have an absorbing crosssection that is 22 times larger than the particles emitted when light-duty vehicles consume a $\mathrm{kg}$ of gasoline. (This factor is 85 times on a per km driven basis.) By comparison, the $\mathrm{CO}_{2}$ emission rates from $\mathrm{MD} / \mathrm{HD}$ diesel and $\mathrm{LD}$ gasoline vehicles, respectively, are $4.17 \mathrm{~kg} \mathrm{CO}_{2}$ per $\mathrm{kg}$ diesel fuel and $3.64 \mathrm{~kg} \mathrm{CO}_{2}$ per $\mathrm{kg}$ gasoline fuel $(E P A, 2005)$.

An estimated $45 \mathrm{Tg}$ of gasoline and $9 \mathrm{Tg}$ of diesel were consumed in CA in 2006 (U.S. DOT, 2006). Based on these values, gasoline vehicles emitted $164 \mathrm{Tg}$ of $\mathrm{CO}_{2}$ and 1 $\mathrm{Tg}$ of $\mathrm{BC}$ in 2006 while diesel trucks emitted $38 \mathrm{Tg}$ of $\mathrm{CO}_{2}$ and $8 \mathrm{Tg}$ of $\mathrm{BC}$. The effective 
absorption cross-section emitted was $9 \times 10^{9} \mathrm{~m}^{2}$ for gasoline vehicles compared with 40 $\mathrm{x} 10^{9} \mathrm{~m}^{2}$ for diesel trucks. Thus, we infer that diesel trucks contribute more to the aerosolinduced warming of the atmosphere and less to the $\mathrm{CO}_{2}$-induced warming of the atmosphere than do gasoline vehicles in California. Since on-road use of diesel fuel in California has been increasing about 3 times faster than gasoline (Harley et al., 2005), the relative importance of diesel emissions is increasing.

While the above analysis considers the light-absorption of freshly emitted particles, we note that optical properties of particles change while residing in the atmosphere. Most notably, there is growing evidence that the absorption efficiency of BC increases as it becomes chemically and physically transformed after emission [(Bond and Bergstrom, 2006; Jacobson, 2001a); (Schnaiter et al., 2005), Mikhailov et al. 2006].

Climate models are only now beginning to address the full effects of light-absorbing BC (Hansen, 2005b; Jacobson, 2001b; Ramanathan and Carmichael, 2008).

\section{Summary and Conclusions}

Particulate emissions from motor vehicles in the Caldecott tunnel were characterized in 2004 and 2006. Optical properties in 2004 were similar to those measured in 2006. Good correlation between PM and aerosol optical properties, especially extinction and absorption coefficients, indicates that routine particle measurements such as $\mathrm{PM}$ and $\mathrm{BC}$ mass may be used as a proxy for optical properties of fresh vehicular emissions. Particle size distributions and optical properties were insensitive to increases in relative humidity up to values in excess of $90 \%$, reinforcing previous findings that freshly emitted motor vehicle particulate matter is hydrophobic. 
Optical property emission factors, expressed as optical cross-section per mass of fuel burned (in $\mathrm{m}^{2} \mathrm{~kg}_{-}$fuel ${ }^{-1}$ ), are reported separately for $\mathrm{LD}$ vehicles and diesel trucks and can be used to infer the climate effects of motor vehicle particulate matter emissions. The amount of absorbing aerosol emitted $\left(4.4 \mathrm{~m}^{2} \mathrm{~kg}_{-}\right.$fuel ${ }^{-1}$ from MD/HD diesel trucks and 0.2 $\mathrm{m}^{2} \mathrm{~kg}_{-}$fuel ${ }^{-1}$ from LD vehicles) and the low values of single scattering albedo (0.2 for diesel and 0.3 for gasoline fueled vehicles) indicates that particulate matter from motor vehicles exerts a positive (i.e., warming) radiative forcing and that the impact of $\mathrm{MD} / \mathrm{HD}$ diesel trucks is greater than LD vehicles. The absorption efficiency of black carbon particles was higher when emitted from LD vehicles rather than diesel trucks - 9.2 versus $5.1 \mathrm{~m}^{2} \mathrm{~g}_{\mathrm{BC}}{ }^{-1}$. Since both the ratios of BC:TC and BC:PM were higher for the diesel trucks, this may indicate that the greater proportion of light-scattering organic carbon in particles from gasoline vehicles results in an enhancement in the amount of light absorbed by the black carbon. These measurements are an important step in providing regulators and policy makers with estimates of the relative effects of gasoline and diesel trucks on climate change.

\section{Acknowledgements}

The authors wish to acknowledge the financial support of the California Air Resources Board (CARB) and NASA's Radiation Sciences Program. LBNL authors Kirchstetter and Lunden were also supported by the Director, Office of Science, Office of Basic Energy Sciences, of the U.S. Department of Energy under Contract No. DE-AC0205CH11231. These experiments would not have been possible without the support of the Caltrans Tunnel crew, CARB and the Bay Area Air Quality Management District. The authors especially wish to acknowledge the efforts of Richard Brill, Tina Le, Frank 
Zappa, Rene Castaneda, Eric Stevenson and Gary Kendall. We also wish to acknowledge TSI, Inc. for the loan of a Water Condensation Particle Counter, and especially Stan Kaufman, Maynard Havlicek, and Kathleen Erickson for valuable discussion about the SMPS system. 


\section{References}

Ayala, A., B. Olson, and B. Cantrell, Working quality assurance project plan for Diesel aerosol sampling methodology, pp. 92, Coordinating Research Council, Inc., Alpharetta, GA, 2003.

Ban-Weiss, G., M.M. Lunden, T.W. Kirchstetter, and R.A. Harley, Size-Resolved Particle Number and Volume Emission Factors for On-Road Gasoline and Diesel Motor Vehicles, J. Aerosol Sci., this issue.

Ban-Weiss, G., J.P. McLaughlin, R.A. Harley, A.J. Kean, E. Grosjean, and D. Grosjean, Carbonyl and nitrogen dioxide emissions from gasoline- and Diesel-powered motor vehicles, Environ. Sci. Technol., 42, 3944-3950, 2008a.

Ban-Weiss, G.A., J.P. McLaughlin, R.A. Harley, M.M. Lunden, T.W. Kirchstetter, A.J. Kean, A.W. Strawa, E.D. Stevenson, and G.R. Kendall, Long-Term Changes in Emissions of Nitrogen Oxides and Particulate Matter from On-Road Gasoline and Diesel Vehicles, Atmos. Environ., 42, 220-232, 2008 b.

Bergstrom, R.W., P.B. Russell, and P. Hignett, Wavelength Dependence of the Absorption of Black Carbon Particles: Predictions and Results from the TARFOX Experiment and Implications for the Aerosol Single Scattering Albedo, Journal of the Atmospheric Sciences, 59 (3), 567-577, 2002.

Biwas, S., P. Fine, M. Geller, S. Hering, and C. Sioutas, Performance evaluation of a recently developed water-based condensatoin particle counter, Aerosol Sci. Tech, 39 (5), 419-427, 2005.

Bond, T.C., and R.W. Bergstrom, Light absorbing by carbonaceous particles: An investigative review, Aerosol Sci. Tech, 41 (1), 27-47, 2006.

Bond, T.C., D.G. Streets, K.F. Yarber, S.M. Nelson, J.-H. Woo, and Z. Klimont, A technology-based global inventory of black and organic carbon emissions from combustion, J. Geophys Res., 109, D14203, 2004.

Bruce, C.W., T.F. Stromberg, K.P. Gurton, and J.B. Mozer, Trans-spectral absorption and scatterign of electromagnetic radiation by diesel soot, Applied Optics, 30 (12), 1537-1546, 1991.

CARB, Emission Data by Region (Statewide). California Air Resources Board, 2006.

CEC, Inventory of California Greenhouse Gas Emissions and Sinks: 1990 to 2004. CEC600-2006-013-Sf, California Energy Commission., 2006.

Chung, S., and J.H. Seinfeld, Global distribution and climate forcing of carbonaceous aerosols, J. Geophys. Res., 107 (D19), 4407, 2002.

EPA, EPA420-F-05-001: Emission Facts: Average Carbon Dioxide Emissions Resulting from Gasoline and Diesel Fuel, 2005.

Forster, P., V. Ramaswamy, P. Artaxo, T. Berntsen, R. Betts, D.W. Fahey, J. Haywood, J. Lean, D. Lowe, G. Myhre, J. Nganga, R. Prinn, G. Raga, S. M., and V. Dorland, Changes in Atmospheric Constituents and in Radiative Forcing., in In: Climate Change 2007: The Physical Science Basis. Contribution of Working Group I to the Fourth Assessment Report of the Intergovernmental Panel on Climate, edited by S. Solomon, D. Qin, M. Manning, Z. Chen, M. Marquis, K.B. Averyt, T. M., and M. H.L., Cambridge University Press, Cambridge, 2007. 
Geller, M.D., S.B. Sardar, H. Phuleria, P.M. Fine, and C. Sioutas, Measurement of Particle Number and Mass Concentrations and Size Distributions in a Tunnel Environment, Environ. Sci. \& Technol., 39, 8653-8663, 2005.

Gundel, L.A., R.L. Dod, H. Rosen, and T. Novakov, The relationship between optical attenuation and black carbon concentrations for ambient and source particles, Sci. Tot. Environ., 36, 197-202, 1984.

Hallar, A.G., A.W. Strawa, B. Schmid, E. Andrews, J. Ogren, P.J. Sheridan, R. Ferrare, D. Covert, R. Elleman, H. Jonsson, K. Bokarius, and A.P. Luu, Atmospheric Radiation Measurements Aerosol Intensive Operating Period: Comparison of aerosol scattering during coordinated flights, J. Geophys. Res., 111, 2006.

Hansen, A.D., The Aethalometer, 210 pp., Copyright (C) 2005 Magee Scientific Company, Berkeley, CA, Berkeley, CA, 2005a.

Hansen, J., Efficacy in climate forcing, J. Geophys. Res., 110, 2005 b.

Hansen, J.E., and M. Sato, Trends of measured climate forcing agents, Proc. Natl. Acad. Sci. U.S.A., 98 (14), 14778-14783, 2001.

Harley, R.A., L.C. Marr, J.K. Lehner, and S.N. Giddings, Changes in motor vehicle emissions on diurnal to dead time scales and effects on atmospheric composition, Environ. Sci. Technol., 39, 5356-5362, 2005.

Haywood, J.M., D.L. Roberts, A. Slingo, J.M. Edwards, and K.P. Shine, General circulation model calculations of the direct radiative forcing by anthropogenic sulphate and fossil-fuel soot aerosol, J. Clim., 10, 1526-1577, 1979.

Hering, S., and M. Stolzenburg, A methond for particle size amlification by water condensation in a laminar, thermally diffusive flow, Aerosol Sci. Tech, 39 (5), 428-436, 2005.

Jacobson, M.Z., Global direct radiative forcing due to multicomponent anthropogenic and natural aerosols, J. Geophys. Res., 106 (2), 1551-1568, 2001 a.

Jacobson, M.Z., Strong radiative heating due to the mixing state of black carbon in atmospheric aerosols, Nature, 409, $2001 \mathrm{~b}$.

Japar, S.M., A.C. Szkarlat, and R.A. Gorse, Optical properties of particulate emissions from on-road vehicles, Atmos. Environ., 15 (10-11), 2063-2070, 1981.

Jones, A.M., and R.M. Harrison, Estimation of the emission factors of particle number and mass fractions from traffic at a site were mean vehicle speeds vary over short distances, Atmos. Environ., 40, 7125-7137, 2006.

Ketzel, M., P. Wåhlin, R. Berkowicz, and F. Palmgren, Particle and trace gas emission factors under urban driving conditions in Copenhagen based street and roof-level observations, Atmos. Environ., 37, 2735-2749, 2003.

Kirchstetter, T.W., R.A. Harley, N.M. Kreisberg, M.R. Stolzenburg, and S.V. Hering, On-road measurement of fine particle and nitrogen oxide emissions from lightand heavy-duty motor vehicles, Atmospheric Environment, 33 (18), 2955-2968, 1999.

Kirchstetter, T.W., and T. Novakov, Controled generation of black carbon particles from a diffusin flame and applications in evaluating black carbon measurement methods, Atmos. Environ., 41, 1874-1888, 2007.

Kirchstetter, T.W., T. Novakov, R. Morales, and R. O., Differences in the volatility of organic aerosols in unpolluted tropical and polluted continental atmospheres, $J$. Geophys. Res., 105 (21), 26547-26554, 2000. 
Kirchstetter, T.W., B.C. Singer, R.A. Harley, G.R. Kendal, and W. Chan, Impact of oxygenated gasoline use on California light-duty vehicle emissions, Environ. Sci. Technol., 30, 661-670, 1996.

Kittelson, D.B., Engines and Nanoparticles: A Review, J. Aerosol Sci., 29 (5/6), 575-588, 1998.

Kittelson, D.B., J.P. Johnson, W.F. Watts, Q. Wei, M. Drayton, and D. Paulsen, Diesel Aerosol Sampling in the Atmosphere, SAE Technical Paper Series, 2000--1-2212, 2247-2253, 2000.

Kittelson, D.B., W.F. Watts, and J.P. Johnson, On-road and laboratory evaluation of combustion aerosols - Part 1:Summary of diesel engine results, J. Aerosol Sci., 37, 913-930, 2006a.

Kittelson, D.B., W.F. Watts, J.P. Johnson, J.J. Schauer, and D.R. Lawson, On-road and laboratory evaluation of combustion aerosols - Part 2: Summary of spark ignition engine results, J. Aerosol Sci., 37, 931-949, 2006 b.

Liu, W., S.L. Kaufman, B.L. Osmondson, G.J. Sem, F.R. Quant, and D.R. Oberreit, Water-Based Condensation Particle Counters for Environmental Monitoring of Ultrafine Particles, J. Air \& Waste Manage. Assoc., 56, 444-455, 2008.

Malm, W.C., J.F. Sisler, D. Huffman, R.A. Eldred, and T.A. Cahill, Spatial and seasonal trends in particle concentration and optical extinction in the United States., $J$. Geophys Res., 99, 1347-1370, 1994.

Maricq, M.M., and N. Xu, The effective density and fractal dimension of soot particles from premixed and motor vehicle exhaust, J. Aerosol Sci., 35, 1251-1274, 2004.

Menon, S., Current Uncertainties in Assessing Aerosol Effects on Climate, Annu. Rev. Environ. Resource., 29, 1-30, 2004.

Mulholland, G.W., and N.P. Bryner, Radiometric model of the transmission cellreciprocal nephelometer, Atmos. Environ., 28 (5), 873-887, 1994.

Myhre, G., F. Stordal, K. Restad, and I. Isaksen, Estimates of the direct radiative forcing due to sulphate and soot aerosols, Tellus, Ser. B, 50, 463-477, 1998.

Novakov, T., V. Ramanathan, J.E. Hansen, T.W. Kirchstetter, M. Sato, J.E. Sinton, and J.A. Sathaye, Large historical changes of fossil-fuel black carbon aerosols, Geophys. Res. Lett., 30 (6), 1324, 2003.

O'Keefe, A., and D.A.G. Deacon, Cavity ring-down optical spectrometer for absorption measurements using pulsed laser sources, Rev. Sci. Inst., 59 (12), 2544, 1988.

Park, K., F. Cao, D.B. Kittelson, and P.H. McMurry, Relationship between particle mass and mobility for Diesel exhaust particles, Environ. Sci. Technol., 37, 577-583, 2003.

Petäjä, T., H. Manninen, F. Stratman, G. Mordas, M. Siplia, P. Aalso, H. Vehkamäki, W. Birmili, K. Härmeri, and M. Kulmala, On water condensation particle countersa nd their aplicability to field measurements, Nucleation and Atmosperic Aerosols, 707-710, 2007.

Pozzoli, L., I. Bey, S. Rast, M.G. Schultz, P. Stier, and J. Feichter, Trace gas and aerosol interactions in the fully coupled model of aerosol-chemistry-climate ECHAM5HAMMOZ: 1. Model description and insights from the spring 2001 TRACE-P experiment, J. Geophys Res., 113, 2008.

Ramanathan, V., and G. Carmichael, Global and regional climate changes due to black carbon, Nature Geoscience, 1 (April), 221, 2008. 
Roden, C.A., T.C. Bond, S. Conway, and A.B.O. Pinel, Emission factors and real-time optical properties of particles emitted from traditional wood burning cookstoves, Environ. Sci. Technol., 40, 7650-6757, 2006.

Rose, D., B. Wehner, M. Ketzel, C. Engler, J. Voigtländer, T. Tuch, and A. Wiedensohler, Atmospheric number size distributions of soot particles and estimation of emission factors, Atmos. Chem. Phys., 6, 1021-1031, 2006.

Sato, M., J. Hansen, D. Koch, A. Lacis, R. Ruedy, O. Dubovik, B.N. Holben, M. Chin, and T. Novakov, Global atmospheric balck carbon inferred from AERONET, Proc. Natl. Acad. Sci. U.S.A., 100 (11), 6319-6324, 2003.

Schmid, B., R. Ferrare, C. Flynn, R. Elleman, D. Covert, A.W. Strawa, E.J. Welton, D. Turner, H. Jonsson, J. Redemann, J. Eilers, A.G. Hallar, M. Clayton, J. Michalsky, A. Smirnov, B.N. Holben, and J. Barnard, How well do state-of-theart techniques measuring the vertical profile of tropospheric aerosol extinction compare?, J. Geophys. Res., 111, 2006.

Schnaiter, M., C. Linke, O. Mohler, K. Naumann, H. Saathoff, R. Wagner, and U. Schurath, Absorptoin amplification of black carbon internally mixed with secondary organic aerosol, J. Geophys Res., 110, D19204, 2005.

Strawa, A.W., R. Castaneda, T. Owano, D.S. Baer, and B.A. Paldus, The measurement of aerosol optical properties using continuous wave cavity ring-down techniques, $J$. Atmos. Oceanic Tech., 20 (April), 454-465, 2003.

Strawa, A.W., R. Elleman, A.G. Hallar, D. Covert, K. Ricci, R. Provencal, T. W. Owano, H.H. Jonsson, B. Schmid, A.P. Luu, K. Bokarius, and E. Andrews, In-Situ Measurement of Aerosol Optical Properties Made During the DOE Aerosol IOP: 1. Comparison of Extinction and Scattering Coefficients, J. Geophys. Res., 111, 2006.

Szkarlat, A.C., and S.M. Japar, Light absorption by airborne aerosol: Comparison of integrating plate and spectrophone techniques, Applied Optics, 20, 1151-1155, 1981.

TSI, I., Condensation Particle Counter brocher, TSI, Inc., 2009.

U.S. DOT, F.H.A., ANNUAL VEHICLE DISTANCE TRAVELED IN MILES AND RELATED DATA - 2006, 2006.

van de Hulst, H.C., Light Scattering by Small Particles, Dover, New York, 1957.

Verma, S., J. Worden, S. Payra, L. Jourdain, and S. C, Characterizing the long-range transport of black carbon aerosols during Transport and Chemical Evolution over the Pacific (TRACE-P) experiment, Environ. Mon. and Ass., 2008.

Watson, J., J. Chow, and L. Chen, Summary of organic and elemental carbon/black carbon analysis methods and intercomparisons, Aerosol and Air Quality Res., 5, 65-102, 2005.

Wehner, B., U. Uhrner, S. von Löwis, M. Zallinger, and A. Wiedensohler, Aerosol number size distributions within the exhaust plume of a diesel and a gasoline passenger car under on-road conditions and determination of emission factors, Atmos. Environ., 43, 1235-1245, 2009.

Weingartner, E., C. Keller, W.A. Stahel, H. Burtscher, and U. Baltensperger, Aerosol Emission in a Road Tunnel, Atmos. Environ., 31 (3), 451, 1997. 
Tables

\begin{tabular}{|c|c|c|c|c|c|c|c|c|c|}
\hline \multicolumn{10}{|c|}{ Table 1. IOP and Average Particulate Measurements } \\
\hline Date & Bore & $\begin{array}{l}\text { PM } \\
2.5\end{array}$ & TC & BC & $\begin{array}{c}\text { Aeth } \\
\text { BC }\end{array}$ & $\sigma_{\mathrm{pe}}$ & $\sigma_{\mathrm{ps}}$ & $\sigma_{\mathrm{pa}}$ & $\omega$ \\
\hline & & $\mu \mathrm{g}-\mathrm{m}-{ }^{3}$ & $\mu \underset{3}{\mu g-m-}$ & $\mu \mathrm{g}-\mathrm{m}-$ & $\mu \mathrm{g}-\mathrm{m}-{ }^{3}$ & $\mathrm{Mm}^{-1}$ & $\mathrm{Mm}^{-1}$ & $\mathrm{Mm}^{-1}$ & \\
\hline Jul 18 & mixed & 84.8 & 58.2 & 41.9 & 48.4 & $356.4 \pm 7.1$ & $90.6 \pm 6.3$ & $262.2 \pm 18.3$ & $0.25 \pm 0.02$ \\
\hline Jul 19 & mixed & 101.3 & 54.4 & 36.2 & 44.5 & $341.0 \pm 6.8$ & $79.4 \pm 5.6$ & $252.4 \pm 17.6$ & $0.23 \pm 0.02$ \\
\hline Jul 20 & mixed & 82.3 & 55.5 & 39.1 & 49.2 & $344.8 \pm 6.9$ & $77.7 \pm 5.4$ & $267.1 \pm 18.7$ & $0.23 \pm 0.02$ \\
\hline Jul 21 & mixed & 87.1 & 59.6 & 41.1 & 43.3 & $214.1 \pm 4.3$ & $50.6 \pm 3.4$ & $242.8 \pm 17.0$ & $0.24 \pm 0.02$ \\
\hline Jul 24 & mixed & 110.3 & 73.0 & 50.8 & 51.2 & $359.7 \pm 7.2$ & $80.5 \pm 5.6$ & $267.4 \pm 18.7$ & $0.22 \pm 0.02$ \\
\hline Jul 25 & mixed & 97.3 & 65.1 & 44.7 & 47.5 & $354.3 \pm 7.1$ & $91.0 \pm 6.4$ & $263.2 \pm 18.4$ & $0.26 \pm 0.02$ \\
\hline Jul 26 & mixed & 61.9 & 48.3 & 32.6 & 32.3 & $221.6 \pm 4.4$ & $58.7 \pm 4.1$ & $162.9 \pm 11.4$ & $0.26 \pm 0.02$ \\
\hline Jul 27 & mixed & 78.8 & 58.1 & 41.3 & 41.5 & $290.2 \pm 5.8$ & $75.7 \pm 5.3$ & $214.5 \pm 15.0$ & $0.26 \pm 0.02$ \\
\hline AVG & mixed & 88.0 & 59.0 & 41.0 & 44.7 & $310.2 \pm 6.2$ & $75.5 \pm 5.3$ & $241.6 \pm 16.9$ & $0.24 \pm 0.02$ \\
\hline Aug 03 & LDV & 43.4 & 21.2 & 9.0 & 13.9 & $147.6 \pm 3.0$ & $49.9 \pm 3.5$ & $97.7 \pm 6.8$ & $0.34 \pm 0.02$ \\
\hline Aug 07 & LDV & 36.9 & 15.8 & 7.9 & 8.8 & $103.4 \pm 2.1$ & 35.22 .5 & $68.2 \pm 4.8$ & $0.34 \pm 0.02$ \\
\hline Aug 08 & LDV & 39.4 & 27.2 & 14.2 & 15.4 & $155.3 \pm 3.1$ & $53.6 \pm 3.8$ & $100.5 \pm 7.0$ & $0.35 \pm 0.02$ \\
\hline Aug 09 & LDV & 59.4 & 28.3 & 13.6 & 17.2 & $202.2 \pm 4.0$ & $63.8 \pm 4.5$ & $138.8 \pm 9.7$ & $0.32 \pm 0.02$ \\
\hline Aug 10 & LDV & 51.9 & 21.4 & 11.7 & 15.1 & $168.7 \pm 3.4$ & $60.4 \pm 4.2$ & $110.8 \pm 7.7$ & $0.36 \pm 0.02$ \\
\hline AVG & LDV & 46.2 & 22.8 & 11.3 & 14.08 & $155.5 \pm 3.1$ & $52.6 \pm 3.7$ & $103.2 \pm 7.2$ & $0.34 \pm 0.02$ \\
\hline
\end{tabular}

Strawa et al., Optical properties from on-road vehicles 


\begin{tabular}{|c|c|c|c|c|c|c|c|c|}
\hline & & LD vehicles & $\begin{array}{c}\mathrm{MD} / \mathrm{HD} \\
\text { diesel }\end{array}$ & $\begin{array}{c}\text { diesel/ } \\
\text { gasoline }\end{array}$ & & $\begin{array}{c}\mathrm{LD} \\
\text { vehicles }\end{array}$ & $\begin{array}{c}\text { MD/HD } \\
\text { diesel }\end{array}$ & $\begin{array}{c}\text { diesel/ } \\
\text { gasoline }\end{array}$ \\
\hline BC & $g-k g_{f}^{-1}$ & $0.022 \pm 0.004$ & $0.86 \pm 0.07$ & 39.09 & $\mathrm{~g}-\mathrm{km}^{-1}$ & 0.002 & 0.253 & 150.61 \\
\hline$\overline{\mathbf{O M}}$ & $g-k g_{f}^{-1}$ & $0.031 \pm 0.005$ & $0.41 \pm 0.07$ & 13.23 & $\mathrm{~g}-\mathrm{km}^{-1}$ & 0.002 & 0.121 & 50.96 \\
\hline $\mathbf{P M}_{2.5}$ & $g-k g_{f}^{-1}$ & $0.07 \pm 0.02$ & $1.4 \pm 0.3$ & 20.00 & $\mathrm{~g}-\mathrm{km}^{-3}$ & 0.005 & 0.412 & 77.06 \\
\hline $\mathbf{E F}_{\mathrm{e}}$ & $\mathrm{m}^{2}-\mathrm{kg}_{\mathrm{f}}^{-1}$ & $0.29 \pm 0.05$ & $5.6 \pm 1.0$ & 19.31 & $\mathrm{~m}^{2}-\mathrm{km}^{-1}$ & 0.022 & 1.647 & 74.40 \\
\hline$\overline{\mathbf{E F}_{\mathrm{s}}}$ & $\mathrm{m}^{2}-\mathrm{kg}_{\mathrm{f}}^{-1}$ & $0.09 \pm 0.009$ & $1.1 \pm 0.2$ & 12.22 & $\mathrm{~m}^{2}-\mathrm{km}^{-1}$ & 0.007 & 0.324 & 47.09 \\
\hline $\mathbf{E F}_{\mathbf{a}}$ & $\mathrm{m}^{2}-\mathrm{kg}_{\mathrm{f}}^{-1}$ & $0.2 \pm 0.05$ & $4.4 \pm 0.8$ & 22.00 & $\mathrm{~m}^{2}-\mathrm{km}^{-1}$ & 0.015 & 1.294 & 84.76 \\
\hline MEE & $\mathrm{m}^{2}-\mathrm{g}_{\mathrm{PM}}{ }^{-1}$ & $4.17 \pm 1.38$ & $3.99 \pm 1.12$ & 0.96 & $\mathrm{~m}^{2}-\mathrm{km}^{-1}$ & 0.318 & 1.174 & 3.69 \\
\hline MSE & $\mathrm{m}^{2}-\mathrm{g}_{\mathrm{PM}}{ }^{-1}$ & $1.29 \pm 0.39$ & $0.78 \pm 0.24$ & 0.60 & $\mathrm{~m}^{2}-\mathrm{km}^{-1}$ & 0.098 & 0.229 & 2.33 \\
\hline $\mathbf{M A E}_{\mathbf{P M}}$ & $\mathrm{m}^{2}-\mathrm{g}_{\mathrm{PM}}{ }^{-1}$ & $2.9 \pm 1.07$ & $3.14 \pm 0.88$ & 1.08 & $\mathrm{~m}^{2}-\mathrm{km}^{-1}$ & 0.221 & 0.924 & 4.17 \\
\hline $\mathbf{M A E}_{\mathbf{B C}}$ & $\mathrm{m}^{2}-\mathrm{g}_{\mathrm{BC}}{ }^{-1}$ & $9.23 \pm 2.07$ & $5.12 \pm 0.93$ & 0.55 & $\mathrm{~m}^{2}-\mathrm{km}^{-1}$ & 0.705 & 1.506 & 2.14 \\
\hline$\omega$ & ND & $0.31 \pm 0.17$ & $0.20 \pm 0.18$ & - & & & & \\
\hline
\end{tabular}

Strawa et al., Optical properties from on-road vehicles 


\begin{tabular}{|l|l|l|}
\hline \multicolumn{3}{|l|}{ Table 3. Comparison of dry versus wet extinction and volume mean diameter for 2006. } \\
\hline RH & Extinction & Volume Mean Diameter \\
\hline MD/HDV Bore & & \\
\hline 22.4 & 103.4 & 204.2 \\
\hline 92.2 & 103.6 & 202.1 \\
\hline LDV Bore & & \\
\hline 23.6 & 289.7 & - \\
\hline 90.8 & 262.2 & - \\
\hline
\end{tabular}


Figure

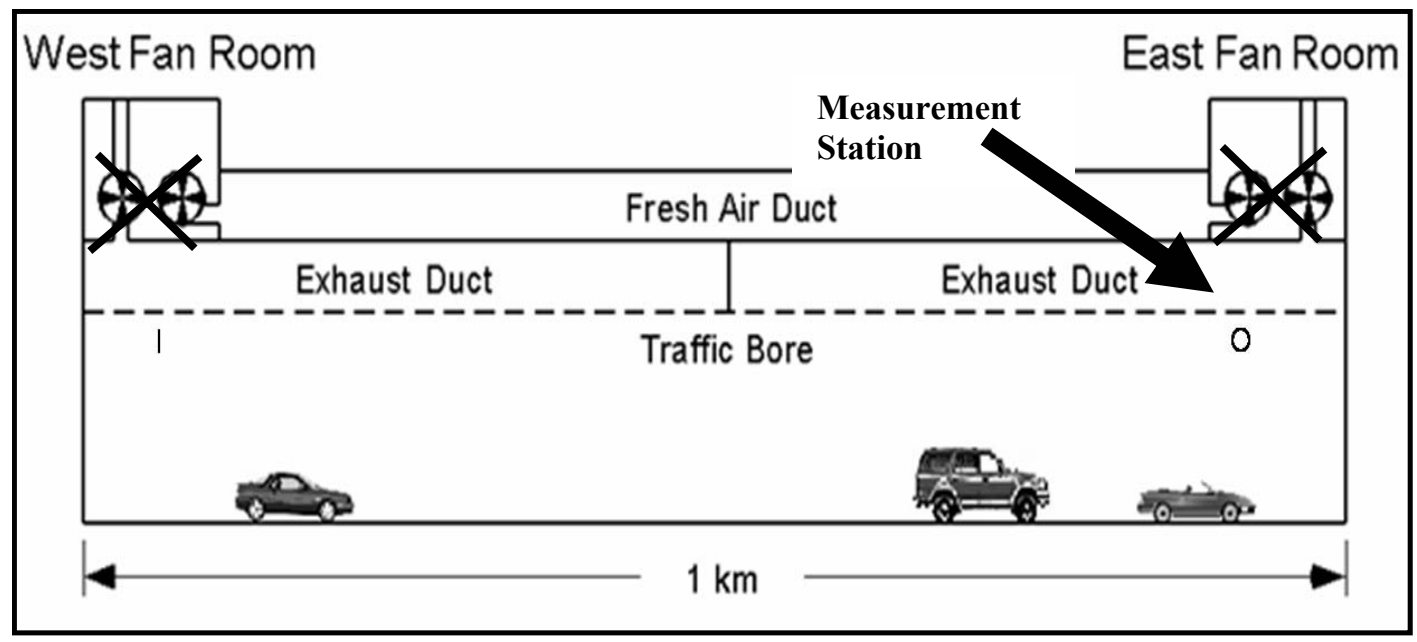

Figure 1. Schematic of Caldecott Tunnel. 


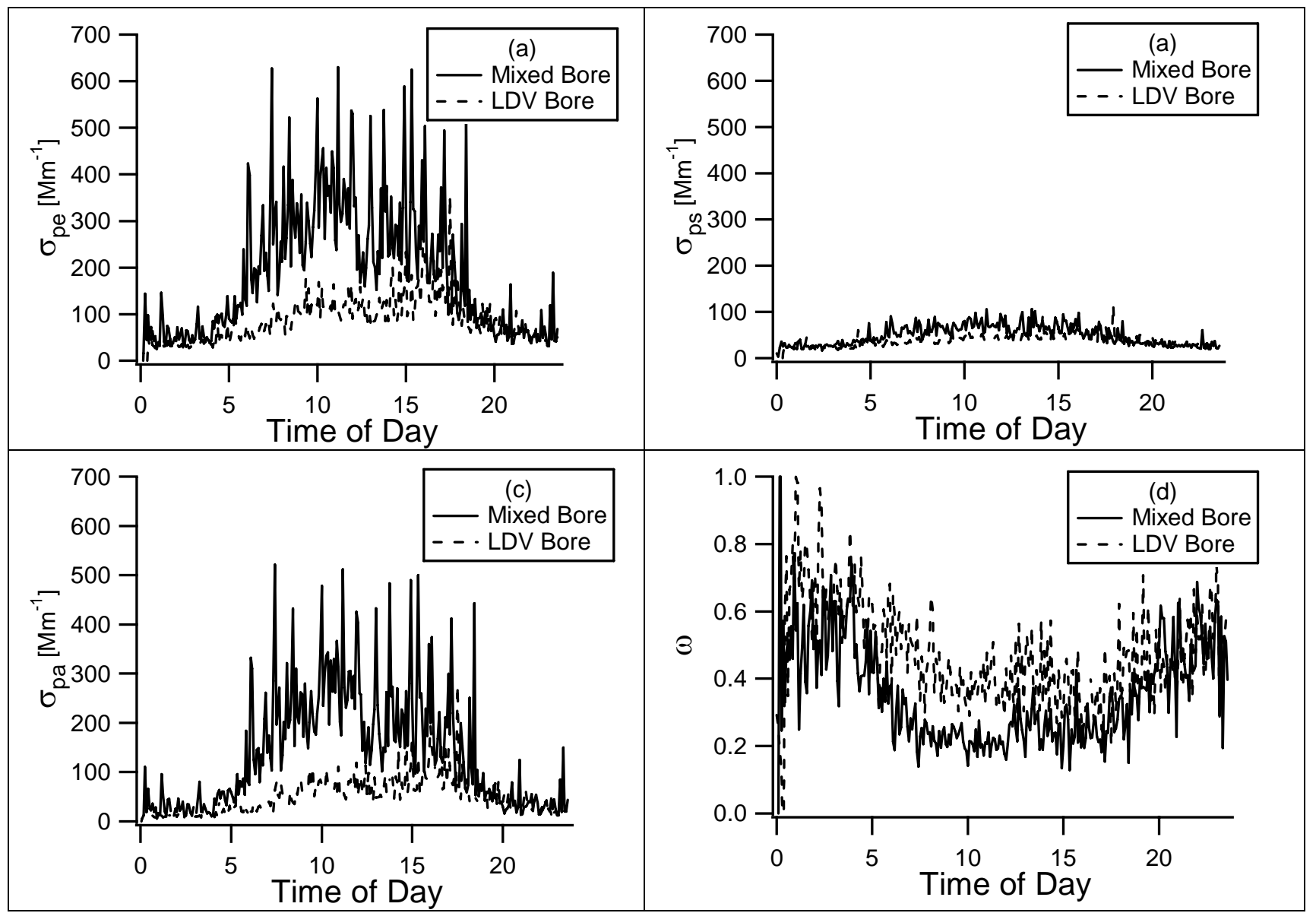

Figure 2. Measured and calculated optical properties obtained in the Caldecott Tunnel in summer of 2006. Measurements were made in bore 2 (mixed traffic) prior to 3 Aug. 2006 and in bore 1 (LDV-only) after 3 Aug. 2006. The absorption coefficient was obtained by subtracting the measured scattering from the measured extinction coefficients. Time of day is listed in hour relative to local time. 


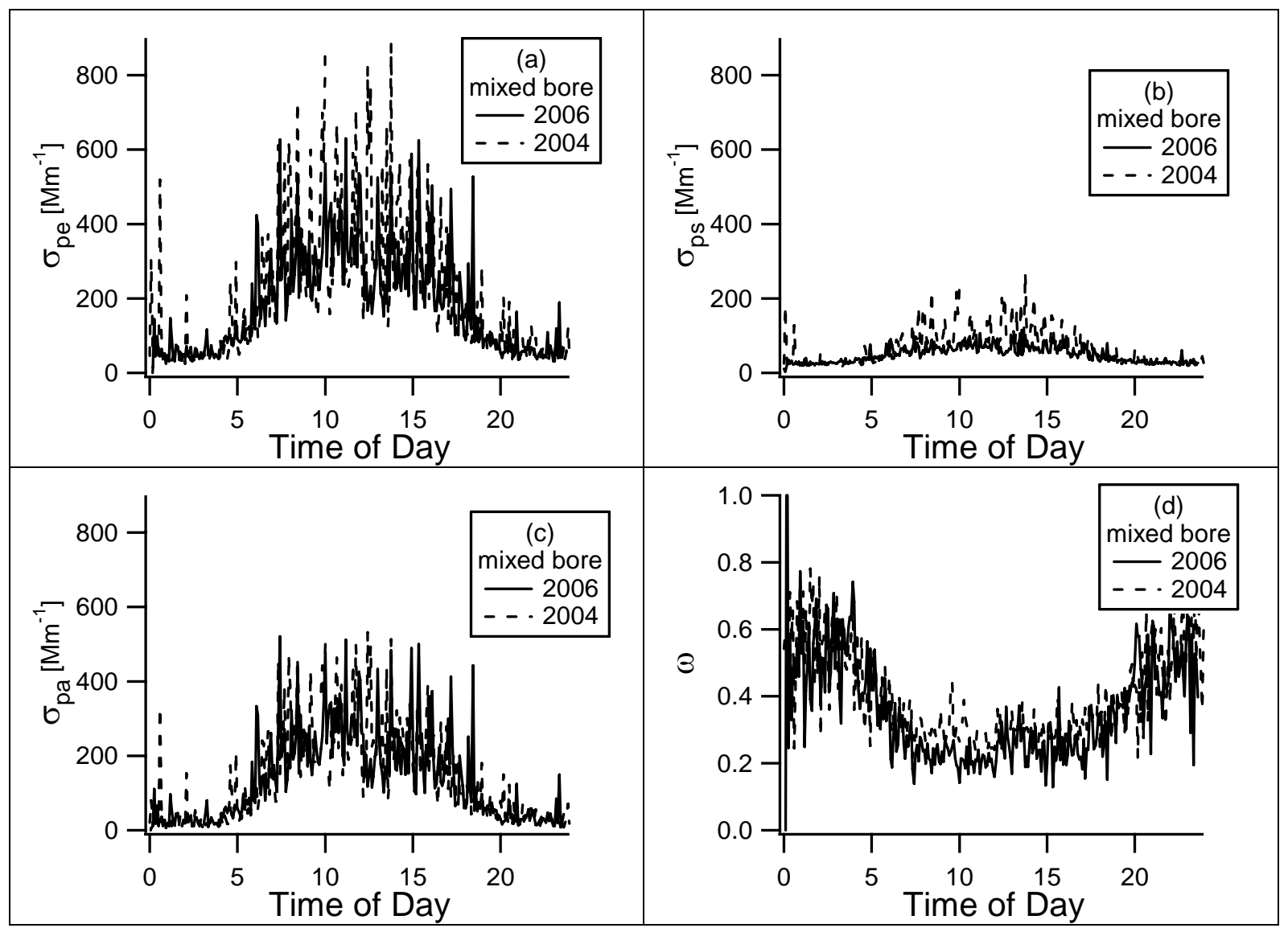

Figure 3. Comparison of optical property measurements made in 2004 and 2006 in the mixed traffic bore. (a) extinction, (B) scattering and (c) absorption coefficients and (d) single scattering albedo 


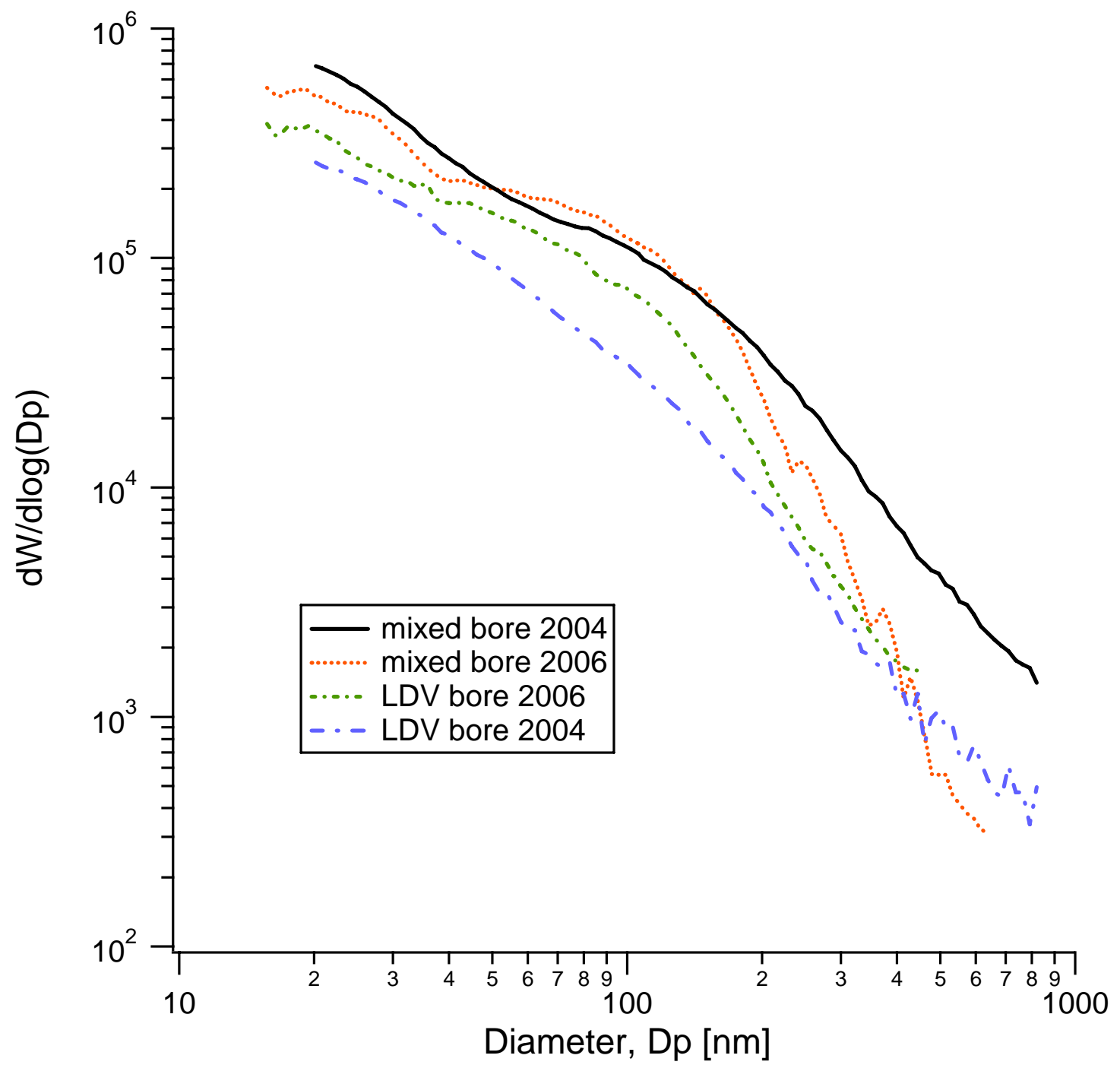

Figure 4. Average size distributions measured during the 2004 and 2006 IOPs. 


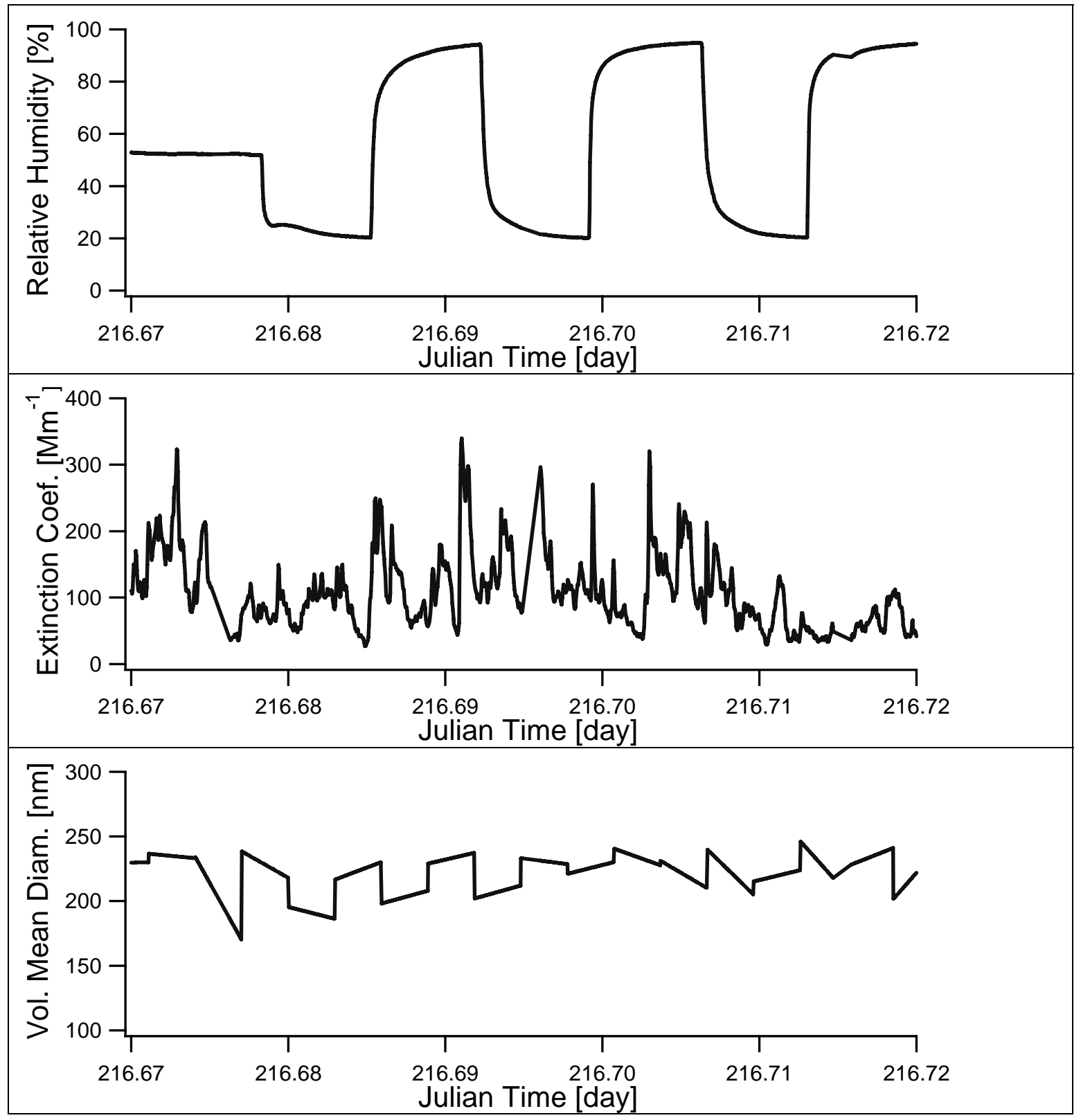

Figure 5. Example of fRH scans showing that there is no change in either extinction coefficient or volume mean diameter for changes in RH, taken on 4 Aug. 2006 in the $\mathrm{MD} / \mathrm{HD}$ bore. 


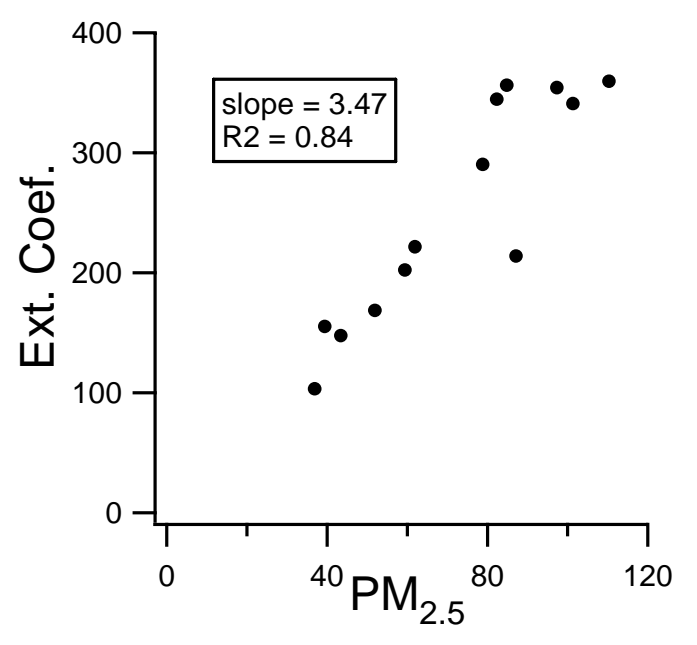

(a)

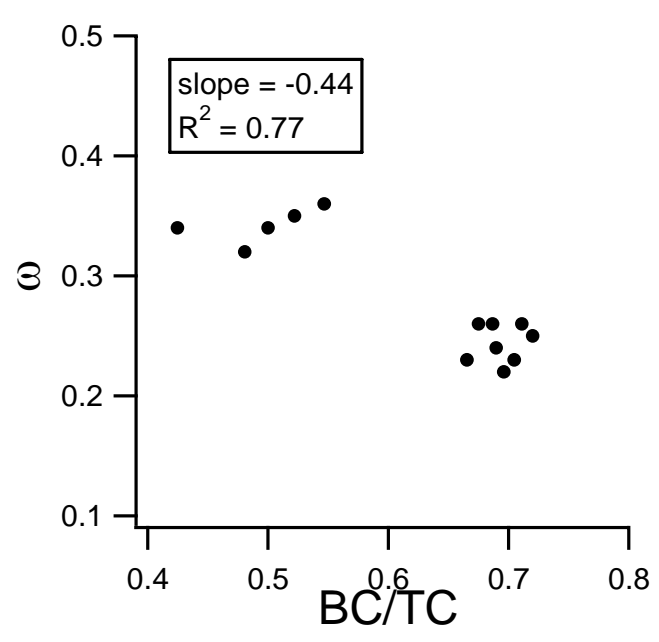

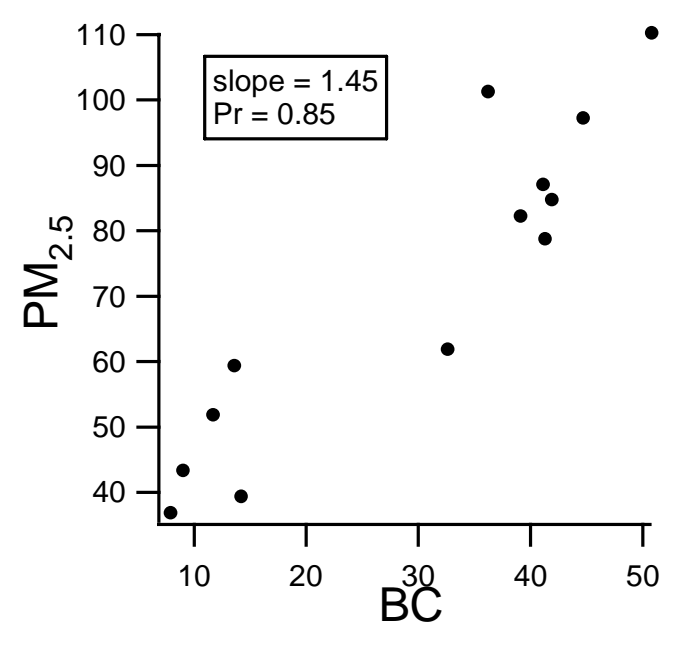

(c)

(b) 
Figure 6. Correlations between particle measurements and optical properties. a)

Gravimetric $\mathrm{PM}_{2.5}$ correlates with extinction coefficient, b) single scattering albedo vs, $\mathrm{BC} / \mathrm{TC}$ ratio, and c) total carbon and $\mathrm{PM}_{2.5}$ vs $\mathrm{BC}$. 

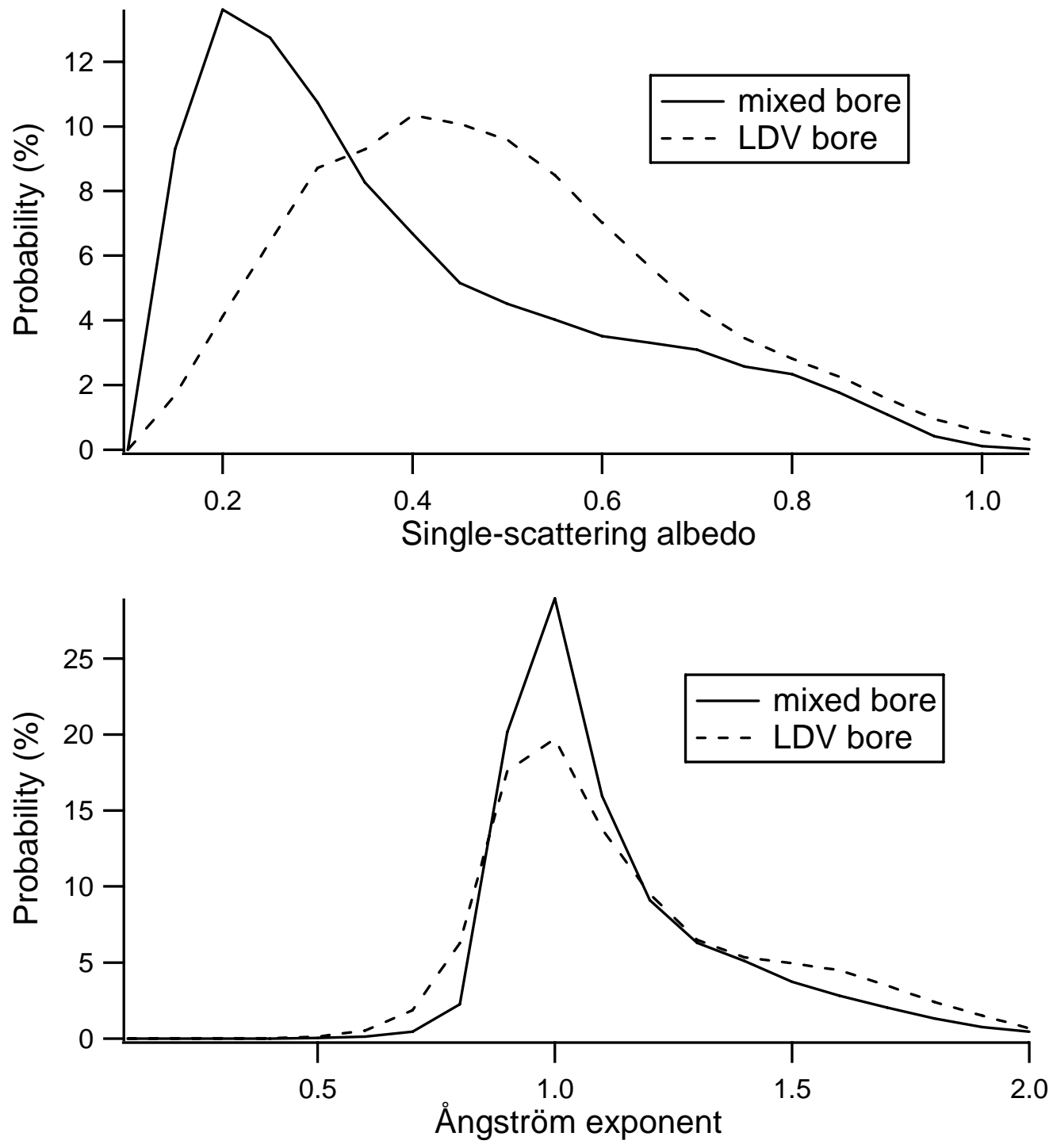

Figure 7. Probability density functions for (a) single scattering albedo and (b) Ångström exponent. 